\title{
Lineide Salvador Mosca: trajetória acadêmica e contribuições para o campo da retórica e argumentação
}

\section{Maria Helena Cruz Pistori}

Pós-Doutoranda em Estudos Linguísticos pela Pontifícia Universidade Católica de São Paulo, Brasil http://orcid.org/0000-0003-0751-3178

\section{Isabel Cristina Michelan Azevedo}

Docente da Universidade Federal de Sergipe, Brasil http://orcid.org/0000-0002-5293-0168

\section{Eduardo Lopes Piris}

Docente da Universidade Estadual de Santa Cruz, Brasil http://orcid.org/0000-0003-3718-8126

Resumo: Dedicamos este artigo à memória da Professora Lineide Salvador Mosca, que iniciou a pesquisa sobre retórica e argumentação na Universidade de São Paulo. Neste artigo, pretendemos sublinhar a importância do trabalho de Lineide Mosca para a consolidação do campo de investigação da argumentação retórica no Brasil. Para isso, abordamos elementos de sua biografia e de seu percurso intelectual, organizando dados relativos às suas orientações de pesquisa e às suas publicações mais relevantes. Esperamos que este artigo possa realçar a dimensão acadêmica e afetiva da pesquisadora homenageada, assim como apresentar um roteiro de leitura da obra de uma das pioneiras dos estudos discursivo-argumentativos no Brasil.

Palavras-chave: Lineide Mosca. GERAR. Argumentação. Retórica. Discurso.

Abstract: We dedicate this article to the memory of Professor Lineide Salvador Mosca, who started research on rhetoric and argumentation at the University of São Paulo. In this article, we intend to underline the importance of Lineide Mosca's work for the consolidation of the field of investigation of rhetorical argumentation in Brazil. For this, we approach elements of his biography and his intellectual path, organizing data related to his research guidelines and to his most relevant publications. We hope that this article can highlight to the reader the academic and affective dimension of the honored researcher and a script for reading the work of one of the pioneers of discursive-argumentative studies in Brazil.

Keywords: Lineide Mosca. GERAR. Argumentation. Rhetoric. Discourse. 
Tem-se, cada vez mais, consciência de que fundamental é considerar a diferença, o outro presente em cada um e de que resulta um equilíbrio bem mais salutar no jogo de influências [retóricas] a que estamos todos expostos (Lineide Mosca, 1997b, p. 6).

\section{Introdução}

Neste momento de profunda tristeza pela perda da Profa. Dra. Lineide do Lago Salvador Mosca (1941-2021), este texto, redigido por aqueles que tiveram a oportunidade de privar tanto de seu conhecimento como de sua amizade, destaca seu estilo único de ser e agir, que permanecerá presente nas pessoas e nos trabalhos em torno da argumentação no Brasil. Mais do que isso, por meio do levantamento de sua carreira acadêmica - produções, cursos ministrados, orientações etc. - pretendemos destacar seu legado aos estudos de Retórica e Argumentação no Brasil. Tal legado se consubstancia não apenas nas produções escritas que conhecemos e estão registradas em seu currículo, mas também nos vínculos entre gerações de pesquisadores que constituiu, numa "genealogia acadêmica" que mostra os "filhos" que ajudou a formar, que, por sua vez, podem gerar “netos”, e assim por diante (Pesquisas FAPESP, 2016)1.

Este artigo não pretende fazer uma análise dos saberes produzidos pela Professora Lineide, mas apenas antecipar, em cinco seções, um mapeamento de sua produção acadêmica, passando por elementos como vida e carreira, percurso intelectual, orientações de pesquisa, publicações mais relevantes e constituição do seu grupo de pesquisa. Desse modo, apresentamos na seção 1 dados gerais de sua vida e carreira acadêmico-profissional. Em seguida, na seção 2, trazemos dados relativos ao seu percurso intelectual, informando características de suas pesquisas e discorrendo sobre o vínculo cultivado com vários grupos de pesquisa no Brasil e no exterior, bem como sobre o diálogo com as antigas retóricas e os modos de compreender e atualizar a retórica na contemporaneidade, com destaque para a interdisciplinaridade. Na seção 3, destacamos e organizamos as orientações de mestrado e doutorado realizadas durante duas décadas na FFLCH/USP. Na seção 4, dedicamos nossa atenção à sua produção acadêmica, relacionando livros, capítulos, artigos, traduções e outras produções. Na seção 5, tratamos do Grupo de Estudos de Retórica e Argumentação (GERAR), grupo dinâmico revelador de sua capacidade de aglutinar pesquisadores e estudantes em torno de seu projeto de pesquisa retórica. Por último, nas

\footnotetext{
1 https://revistapesquisa.fapesp.br/galhos-e-raizes-da-arvore-da-ciencia/
} 
considerações finais, ressaltamos o legado de Lineide Mosca para os estudos de retórica e argumentação no Brasil.

\section{Vida e carreira acadêmica}

A formação em Letras Neolatinas, pela Universidade de São Paulo, em 1963, marca o início da carreira acadêmica de Lineide Mosca. As especializações concluídas nos anos seguintes - Língua e Literatura Francesa, na Universidade de São Paulo (entre 1964 e 1965) e Linguistique Générale et Linguistique Appliquée na Université de Besançon, Faculté de Lettres, como bolsista do governo francês (entre 1965-1966) - indicam seu apreço pela educação e sua disposição para iniciar uma carreira acadêmica.

O início das atividades profissionais de Lineide Mosca no Magistério aconteceu aos vinte e três anos, quando foi integrada ao corpo docente do Ensino Oficial Secundário da cidade de São Paulo e, quatro anos depois, quando assume a disciplina de Linguística Românica na Universidade Federal de Pernambuco, como professora visitante. No início de sua carreira, dividia seus esforços entre o ensino de francês e de filologia, mas, a partir de 1971, com trinta anos, direcionou sua carreira integralmente ao ensino superior.

Após trabalhar com turmas de graduação da Fundação Municipal de Santo André, das Faculdades Associadas do Ipiranga (entre 1971 e 1972), da Universidade Metodista de São Paulo, à qual esteve ligada de 1972 até 1988, e da Universidade Presbiteriana Mackenzie, em 1987, ingressou na Universidade de São Paulo (USP) em 1988, permanecendo como membro permanente da Faculdade de Filosofia, Letras e Ciências Humanas até 2021.

O ingresso na USP aconteceu com o apoio de seu orientador de mestrado - prof. Isaac Nicolau Salum, professor de Filologia Românica, que durante o período de 19721981 esteve muito próximo a ela enquanto Lineide Mosca redigia a dissertação: $O$ adjetivo românico: subsídios para seu estudo. Com o incentivo de Nilce Sant'Anna Martins, orientadora de doutorado, entre 1984 a 1991, Lineide desenvolveu sua tese $A$ subjetividade no editorial: uma análise retórico-argumentativa da adjetivação, inscrevendo sua pesquisa num campo de investigação que assistiria o surgimento e crescimento de uma entusiasta, que viria a contribuir sobremaneira para a consolidação dos estudos da argumentação e da nova retórica na área de Letras.

Como docente da Universidade de São Paulo, Lineide Mosca organizou, em 1994, o curso de difusão cultural (atual extensão universitária) “Retórica e Argumentação”, que constituiu um marco nos estudos de Retórica e Argumentação, ao reunir e articular 
docentes de diversas disciplinas da área de Letras para introduzir o público aos estudos retóricos na Índia Antiga, na Grécia Antiga e no Império Romano, à reinscrição da retórica clássica em abordagens contemporâneas, como a nova retórica, a assuntos específicos como as figuras de retórica e a abordagens linguístico-discursivas, como a argumentação na pragmática e no discurso.

Naquele momento, Lineide Mosca era professora Assistente-Doutor no Departamento de Letras Clássicas e Vernáculas, no Programa de Filologia e Língua Portuguesa, e a repercussão e a importância desse evento fizeram com que, a partir 1996, ela passasse a ministrar na Pós-Graduação a disciplina "Retórica Clássica e Retórica Moderna". Além disso, aquele curso de difusão cultural oferecido em 1994 deu origem à organização do livro Retóricas de ontem e de hoje, com primeira edição publicada em 1997 (como veremos na seção 2).

A importância desse curso se deve também à audiência, que, posteriormente, desempenhou uma função multiplicadora daqueles estudos. Apesar de não termos tido acesso a qualquer documento da época, podemos citar, por exemplo, o levantamento que procedemos entre os integrantes do Grupo de Trabalho "Argumentação" da Anpoll, no qual perguntamos "como você foi introduzido aos estudos da argumentação?".

Nesse levantamento, observamos que estavam presentes no curso de difusão cultural "Retórica e Argumentação" de 1994 a Profa. Dra. Zilda Gaspar de Oliveira Aquino (USP) e o Prof. Dr. Luiz Antônio Ferreira (PUC/SP), respectivamente líderes do Grupo de Estudos do Discurso da USP (GEDUSP/CNPq/USP) e do Grupo de Estudos Retóricos e Argumentativos (ERA/CNPq/PUC-SP), ambos com destacada relevância tanto em publicações quanto em formação de novos pesquisadores.

$E$, nesse aspecto, vale também destacar o trabalho de formação, em distintas frentes e ao longo dos anos, realizado por todos os professores que ensinaram no curso "Retórica e Argumentação" organizado e ministrado pela Profa. Dra. Lineide Mosca em 1994: Prof. Dr. Carlos Alberto Fonseca; Prof. Dr. Mário Ferreira; Profa. Dra. Ísis Borges da Fonseca; Prof. Dr. Ariovaldo Peterlini; Profa. Dra. Elisa Guimarães; Profa. Dra. Helena Hathsue Nagamine Brandão; Profa. Dra. Maria Adélia Ferreira Mauro.

Desse modo, a repercussão do curso de difusão cultural "Retórica e Argumentação" oferecido em 1994 e a criação da disciplina de Pós-Graduação “Retórica Clássica e Retórica Moderna” em 1996 na linha de pesquisa em língua portuguesa fizeram com que a retórica, enquanto objeto de estudo, transbordasse do domínio exclusivo dos estudos clássicos, ligados aos gregos e latinos da Antiguidade e também à literatura, e passasse, junto com a argumentação, a ser conteúdo de um 
curso de língua portuguesa na universidade brasileira, o que é muito significativo para a expansão e a riqueza de abordagens de tal objeto de pesquisa em seu campo de investigação. Atualmente, com o nome Discurso, Retórica e Argumentação, a disciplina é oferecida pelo PPG em Filologia e Língua Portuguesa da USP, na linha de pesquisa Linguística Textual e Teorias do Discurso no Português.

Um capítulo à parte na trajetória de Lineide Mosca refere-se à constituição do Grupo de Pesquisa Retórica e Argumentação (GERAR/CNPq/USP) em 1994, a partir de seu projeto intitulado "Retórica e Argumentação - Exame de procedimentos discursivos", como veremos na seção 5 .

É importante ressaltar, ainda, que sua carreira acadêmica deu expressiva contribuição para a internacionalização universitária, mesmo antes de tal termo ter se imposto como um indicador de avaliação das instituições acadêmicas mundo afora. Em 1995, Lineide Mosca realiza pesquisas de pós-doutorado efetivadas em diferentes países, como França, na École des Hautes Etudes en Sciences Sociales - EHESS, com bolsa FAPESP, e na Sorbonne Nouvelle Paris III; posteriormente, na Bélgica (Université de Liège) e na Alemanha (Ruhr Universität Bochum e Freie Universität Berlin). E foi ainda professora visitante na Universidade de Stanford (Palo Alto-Califórnia). Essa vivência internacional e a construção de redes de cooperação possibilitaram a ida de muitos de seus orientandos de doutorado a fazer o chamado estágio sanduíche, sobretudo, na França, ressaltando, consequentemente, o caráter internacional das pesquisas desenvolvidas por seu grupo GERAR.

Para concluir esse percurso sobre a trajetória acadêmica de Lineide Mosca, destacamos que ela conquistou o grau máximo da carreira docente ao obter o título de Livre-Docente pela Universidade de São Paulo, em 2007, tendo apresentado o trabalho intitulado Discurso, Argumentação e Persuasão - uma revisão crítica.

\section{Percurso intelectual}

Fatos importantes costumam marcar o modo como vemos a passagem do tempo e também o avanço do conhecimento. Um deles, conhecido de todos aqueles que trabalham com a argumentação no discurso, é a publicação das duas obras que reintroduziram e revitalizaram os estudos retóricos na contemporaneidade em 1958: o Tratado da argumentação, de Perelman e Olbrechts-Tyteca, e Os usos do argumento, de Toulmin. No Brasil, na área dos estudos de texto e discurso, os ecos e as ressonâncias desses estudos surgem timidamente, a princípio, mas podemos afirmar que, nas 
disciplinas da área de Letras, mais especialmente nos estudos do discurso, o ano de 1994 também pode ser considerado um marco.

Sabemos que, no Brasil, a eliminação da Retórica e Poética como matérias de ensino havia ocorrido na última década do séc. XIX, havendo apenas "resíduos e sobrevivências" claramente discerníveis no século XX, conforme aponta o minucioso estudo de Souza (1999). Dessa forma, sem dúvida, devemos à Lineide Mosca este impulso inicial dado à revalorização da antiga disciplina, sobretudo porque a retórica é a primeira disciplina que se dedicou aos estudos do discurso. Como bem destaca José Luiz Fiorin (2015, p. 26), "herdar a retórica" nos estudos discursivos hoje, significa "lêla à luz dos problemas teóricos enunciados na atualidade".

Lineide Mosca buscou mostrar a retórica sob essa luz, certamente como fruto de seu projeto de pesquisa “Retórica e Argumentação", de 1995. E, já em 1997, lança a importante obra, Retóricas de ontem e de hoje, organizada por ela, com reimpressões e uma terceira edição em 2004 (hoje esgotada), publicada pela Humanitas, editora da Faculdade de Filosofia, Letras e Ciências Humanas da USP.

É importante notar que, na data em que a obra Retóricas de ontem e de hoje foi publicada, os estudos brasileiros sobre retórica - como disciplina a ser estudada na compreensão da argumentação em língua portuguesa - em nossa universidade eram muito incipientes, e o discurso retórico, de modo geral, sofria ainda amplamente a pecha de discurso vazio e mentiroso (REBOUL, 1996). Esse contexto ressalta a importância da obra, cujo Prefácio é escrito por Jean-Marie Klinkenberg, membro do Groupe $\mu$ e docente do Département d'Études Romanes, da Universidade de Liège (Bélgica), um pesquisador com quem Lineide manteve vínculos ao longo de toda a vida.

Aproximando antigas e novas retóricas, em Retóricas de ontem e de hoje, Lineide Mosca reúne pesquisadores que trabalham com a retórica na Índia Antiga (Carlos Alberto Fonseca e Mário Ferreira), na Grécia Antiga (Ísis Borges B. da Fonseca), e na tradição latina (Ariovaldo Peterlini). Também congrega pesquisadores da Universidade de São Paulo que trabalham com a argumentação, seja com as figuras de retórica (Elisa Guimarães) ou com a pragmática (Helena Hathsue Nagamine Brandão), seja com argumentação e discurso (Maria Adélia Ferreira Mauro).

Seu artigo, o primeiro da obra - "Velhas e novas retóricas: convergências e desdobramentos" -, é esclarecedor do modo como herda e passa a difundir a retórica no estudo do discurso. Lineide Mosca aborda as diferentes disciplinas da linguagem, aquelas que buscam os efeitos de sentido por ela criados, ou as ações que ela promove, ou novas classificações de figuras, ou mesmo novas compreensões do fenômeno argumentativo, como desdobramentos da velha retórica. Segundo ela, seriam as 
retóricas de ontem e de hoje, aliás título sugerido por seu amigo Klinkenberg, tal como revelado pela própria Lineide Mosca em sua conferência “Retórica e Argumentação na trilha do tempo"2 proferida em 13 de outubro de 2020 pelo Canal Discursividades no YouTube, a convite do Prof. Dr. Lucas Nascimento (UEFS).

$\mathrm{Na}$ disseminação dos estudos retóricos, seu interesse inclinou-se ao exame de procedimentos discursivos, tratando tanto da retórica da linguagem como da retórica da cultura, como atesta seu projeto de pesquisa:

O projeto parte do princípio de que o sentido é construído dentro de uma perspectiva cultural, envolvendo o trabalho das diversas linguagens, dentro de um quadro em que a linguagem verbal ocupa lugar de proeminência. Parte-se das concepções da retórica tradicional para chegar a um balanço do estado da arte na atualidade, em que os mais diversos códigos se interligam. Os postulados assumidos levam a um trabalho de natureza interdisciplinar no âmbito das Ciências Humanas, uma vez que envolve crenças, valores, opiniões e hierarquias/preferências. No plano das Ciências da Linguagem, transita-se entre a Pragmática, a Teoria do Texto e do Discurso, as Teorias da Enunciação e a Semiótica Discursiva³.

Elizabete Enz Hubert e Emilson José Bento (2019), na apresentação do livro em homenagem a Lineide Mosca, Retórica e discurso - Fronteiras e interfaces: das origens aos desdobramentos atuais, complementam:

[...] ao fazer um balanço sobre o lugar dos estudos de Retórica e Argumentação na atualidade, [a profa. Lineide] aponta os limites de uma análise que se detenha somente na identificação e descrição dos tipos de argumento, convidando a considerar como ponto de partida analítico a instância da enunciação e de sua cenarização, o que permite acessar o sócio histórico. A enunciação, considerada como defende a pesquisadora, envolve uma dimensão dialética (o logos), uma dimensão estética (o pathos), e uma dimensão ética (o ethos). [...] Com esta amplitude e consequente interdisciplinaridade, os estudos retórico-argumentativos situam-se em um quadro maior, o dos estudos discursivos, o que parece ser uma das grandes contribuições de nossa homenageada (HUBERT; BENTO, 2019, p. 11-12).

Conforme pudemos observar acima, sua abordagem da retórica coloca-a entre os estudos discursivos (argumentativos) contemporâneos, atualizando os estudos tradicionais (por exemplo, acima, no uso de noções como ethos, pathos e logos). Esse enfoque nos estudos discursivos como continuidade dos retóricos lhe permitiu sempre um amplo diálogo com os estudiosos da retórica clássica, como já presente em Retóricas de ontem e de hoje.

\footnotetext{
2 Conferência disponível em: https://www.youtube.com/watch?v=zQt2B211xX4\&ab_channel=Discursividade 3 Ver resumo do projeto de pesquisa disponível no currículo Lattes: http://lattes.cnpq.br/9715573825703718
} 
Outro diálogo importante e permanente que a pesquisadora empreendeu foi aquele com diferentes grupos de pesquisa no exterior. Jean-Marie Klinkenberg (Université de Liège, Bélgica) não apenas prefaciou aquela obra, mas esteve no Brasil, em 2012, respondendo a um convite seu e do Departamento de Linguística da USP. Outros pesquisadores bastante presentes em seus projetos e atividades foram Wolfgang Roth, do Instituts für Romanische Philologie der FU Berlin, Universität Bochum, da Alemanha4; Frans van Eemeren, da Universidade de Amsterdam, Holanda; Louis Panier, da Université Catholique de Lyon e Université Lumière Lyon 2, França; Christian Plantin, Université Lumière Lyon 2, França; Denis Bertrand, da Université Sorbonne Paris VIII, França; Rui Alexandre Grácio, do Centro de Estudos de Comunicação e Sociedade da Universidade do Minho, Portugal. Essa intensa preocupação com a internacionalização da pesquisa de qualidade também fica demonstrada nos inúmeros congressos de que participou e ainda por meio de visitas que fez a diferentes centros de pesquisa ao redor do mundo.

Seu envolvimento no campo da retórica e argumentação foi reconhecido ainda por sua inserção em diferentes comunidades de pesquisadores da argumentação. Lineide foi sócia fundadora e honorária da Sociedade Brasileira de Retórica (SBR) e integrante de seu Conselho Consultivo; também foi associada da International Society for the History of Rhetoric (ISHR), da Organização Ibero-americana de Retórica (OIR) e da Sociedade Latino-americana de Retórica (ALR). Sem dúvida, esse interesse passa também a ser cultivado pelos integrantes do grupo GERAR, que vêm assumindo a responsabilidade de levar as discussões sobre a argumentação em diferentes perspectivas a distintos espaços acadêmicos mundo afora.

\section{As orientações de mestrado e doutorado na FFLCH/USP}

Nesta seção, veremos como as pesquisas acadêmicas orientadas por Lineide Mosca promoveram a interface entre os estudos retórico-argumentativos e os distintos campos de atividade humana. A fim de otimizar a visualização do alcance e da diversidade de interfaces promovidas pelo conjunto dos trabalhos orientados pela pesquisadora, elaboramos três quadros-síntese (Quadros 1, 2 e 3), indicando os campos de atividades pesquisados, os autores e os títulos dos trabalhos, bem como as interfaces teóricas mobilizadas nas dissertações e teses orientadas.

\footnotetext{
${ }^{4}$ Wolfgang Roth prefaciou a obra Discurso, argumentação e produção de sentido, com o texto "A metáfora: um conceito na encruzilhada das disciplinas filológicas", organizada por Lineide Mosca.
} 
No Quadro 1, podemos ver que as dissertações de mestrado orientadas por Lineide Mosca abarcam grande variedade de campos de atividade - Publicidade, Política, Religião, Literatura, Jornalismo, Direito e Educação - e promovem interfaces teóricas, articulando tanto a retórica clássica como a nova retórica com os estudos do discurso, da semiótica, da enunciação, da metáfora conceptual, deixando entrever, portanto, a diversidade de objetos de estudo e de quadros teóricos que foram explorados sob a orientação de Lineide Mosca.

\section{Quadro 1 - Dissertações de Mestrado}

\begin{tabular}{|c|c|c|c|}
\hline \multicolumn{3}{|r|}{ Dados da pesquisa } & \multirow{2}{*}{$\begin{array}{l}\text { Interface teórica } \\
\text { Retórica, } \\
\text { argumentação, } \\
\text { discurso e } \\
\text { enunciação }\end{array}$} \\
\hline \multirow{2}{*}{ 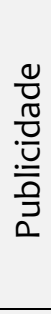 } & \multirow[t]{2}{*}{2000} & $\begin{array}{l}\text { Lúcia Helena Ferreira } \\
\text { A polifonia como recurso retórico-argumentativo no discurso } \\
\text { publicitário }\end{array}$ & \\
\hline & & $\begin{array}{l}\text { Marisa Liete Zicari di Monte } \\
\text { A recriação do lugar-comum no discurso publicitário. A retórica } \\
\text { conotativa em provérbios e clichês }\end{array}$ & $\begin{array}{l}\text { Retórica, } \\
\text { argumentação e } \\
\text { discurso }\end{array}$ \\
\hline \multirow{3}{*}{ 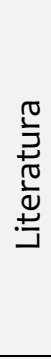 } & 2001 & $\begin{array}{l}\text { Valéria Paz de Almeida } \\
\text { A Retórica de Pedra. Análise da Argumentação no Discurso } \\
\text { Poético de João Cabral de Melo Neto }\end{array}$ & $\begin{array}{l}\text { Retórica e } \\
\text { discurso poético }\end{array}$ \\
\hline & 2004 & $\begin{array}{l}\text { Elaine Vincenzi Silveira } \\
\text { Argumento de autoridade na crônica de Carlos Heitor Cony. Um } \\
\text { enfoque intertextual }\end{array}$ & $\begin{array}{l}\text { Retórica e } \\
\text { discurso }\end{array}$ \\
\hline & 2005 & $\begin{array}{l}\text { Káthia Kobal Benedito } \\
\text { A arte de encantar histórias: um procedimento argumentativo }\end{array}$ & $\begin{array}{l}\text { Retórica e } \\
\text { educação }\end{array}$ \\
\hline \multirow{2}{*}{ 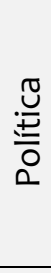 } & 2002 & $\begin{array}{l}\text { Marcelo César Cavalcante } \\
\text { A retórica da sedução em FHC: um estudo argumentativo da } \\
\text { Proposta de Governo para Segundo Mandato }\end{array}$ & $\begin{array}{l}\text { Retórica e } \\
\text { enunciação }\end{array}$ \\
\hline & 2018 & $\begin{array}{l}\text { Maria de Fátima Rollemberg de Faro M. Borelli } \\
\text { Fanatismo e carisma: o uso das definições no discurso de Adolf } \\
\text { Hitler }\end{array}$ & $\begin{array}{l}\text { Retórica, } \\
\text { argumentação e } \\
\text { discurso }\end{array}$ \\
\hline \multirow{3}{*}{ 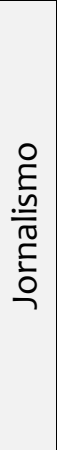 } & 2002 & $\begin{array}{l}\text { Rita de Cássia da Silva } \\
\text { A incerteza no discurso jornalístico do desemprego: um estudo } \\
\text { argumentativo das modalidades nos jornais Gazeta Mercantil e } \\
\text { Valor Econômico }\end{array}$ & $\begin{array}{l}\text { Argumentação e } \\
\text { linguística }\end{array}$ \\
\hline & 2007 & $\begin{array}{l}\text { Andrea Cristina Efangelo Pedretti } \\
\text { Corpo, Racionalidade e emoção: A arte de persuadir em artigos } \\
\text { de revistas femininas }\end{array}$ & $\begin{array}{l}\text { Retórica e } \\
\text { discurso }\end{array}$ \\
\hline & 2018 & $\begin{array}{l}\text { Daniela Lasso de La Vega Pereira } \\
\text { Estratégias retóricas em editoriais jornalísticos on-line: a função } \\
\text { da metáfora como saliência }\end{array}$ & $\begin{array}{l}\text { Retórica e teoria } \\
\text { da metáfora } \\
\text { conceptual }\end{array}$ \\
\hline
\end{tabular}




\begin{tabular}{|c|c|c|c|}
\hline 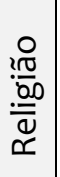 & 2004 & $\begin{array}{l}\text { Márcia Selivon } \\
\text { O discurso da igreja Renascer em Cristo: uma abordagem dos } \\
\text { valores e das estratégias argumentativas }\end{array}$ & $\begin{array}{l}\text { Retórica, } \\
\text { semiótica e } \\
\text { discurso }\end{array}$ \\
\hline$\stackrel{+\%}{\frac{.}{2}}$ & 2007 & $\begin{array}{l}\text { Fabio Souza Trubilhano } \\
\text { Retórica do povo: a construção do discurso persuasivo nos } \\
\text { recursos de infração de trânsito }\end{array}$ & $\begin{array}{l}\text { Retórica e } \\
\text { argumentação }\end{array}$ \\
\hline 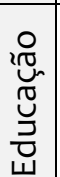 & 2015 & $\begin{array}{l}\text { Camila Alderete Capitani } \\
\text { A operacionalização das teorias de Perelman e de Grácio no } \\
\text { ciclo da pesquisa-ação: uma possibilidade de análise das } \\
\text { situações argumentativas em sala de aula }\end{array}$ & $\begin{array}{l}\text { Retórica e } \\
\text { argumentação }\end{array}$ \\
\hline
\end{tabular}

Fonte: Currículo Lattes de Lineide do Lago Salvador Mosca.

Vejamos como essa tendência formativa se reproduz em suas orientações de teses de doutorado. No Quadro 2, dispomos as pesquisas produzidas na primeira década de 2000 e relacionamos os trabalhos defendidos nos anos 2010 no Quadro 3.

Quadro 2 - Teses de Doutorado (primeiro decênio dos anos 2000)

\begin{tabular}{|c|c|c|c|}
\hline & \multicolumn{2}{|r|}{ Dados da pesquisa } & Interface \\
\hline \multirow{3}{*}{ 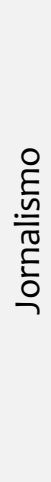 } & 2000 & $\begin{array}{l}\text { Ramon Américo Vasques } \\
\text { As modalidades linguísticas na argumentação de editoriais } \\
\text { jornalísticos }\end{array}$ & $\begin{array}{l}\text { Argumentação } \\
\text { e semântica }\end{array}$ \\
\hline & 2005 & $\begin{array}{l}\text { Cladir Costa Gabriel Garcia } \\
\text { A política do Riso e o riso da Política. A argumentatividade na } \\
\text { expressão do humor no discurso jornalístico }\end{array}$ & $\begin{array}{l}\text { Argumentação } \\
\text { e enunciação }\end{array}$ \\
\hline & 2006 & $\begin{array}{l}\text { Valéria Paz de Almeida } \\
\text { Nas redes dos telejornais: o tecido discursivo e a formação de } \\
\text { memória social }\end{array}$ & $\begin{array}{l}\text { Argumentação } \\
\text { e análise do } \\
\text { discurso }\end{array}$ \\
\hline \multirow{3}{*}{ 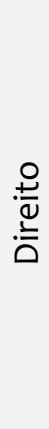 } & 2003 & $\begin{array}{l}\text { Antônio Henriques } \\
\text { A dimensão retórico-jurídica nos autos religiosos de Gil Vicente }\end{array}$ & Retórica \\
\hline & 2003 & $\begin{array}{l}\text { Yêda de Moraes Camargo } \\
\text { A retórica do discurso jurídico - Um estudo das interrogativas no } \\
\text { julgamento de Gregório Fortunato }\end{array}$ & $\begin{array}{l}\text { Retórica, } \\
\text { argumentação } \\
\text { e discurso }\end{array}$ \\
\hline & 2008 & $\begin{array}{l}\text { Maria Helena Cruz Pistori } \\
\text { Persuasão e eficácia discursiva no direito: modos de ser, modos } \\
\text { de dizer }\end{array}$ & $\begin{array}{l}\text { Retórica, } \\
\text { argumentação } \\
\text { e semiótica }\end{array}$ \\
\hline
\end{tabular}




\begin{tabular}{|c|c|c|c|}
\hline \multirow{2}{*}{ 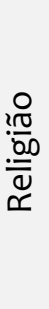 } & 2007 & $\begin{array}{l}\text { Marcelo Silveira - O discurso da teologia da prosperidade em } \\
\text { lgrejas Evangélicas Pentecostais. Estudo da retórica e da } \\
\text { Argumentação no culto religioso }\end{array}$ & $\begin{array}{l}\text { Retórica, } \\
\text { argumentação } \\
\text { e discurso }\end{array}$ \\
\hline & 2008 & $\begin{array}{l}\text { Heitor Bittencourt Filho } \\
\text { A enunciação do discurso religioso. Leitura/Análise do texto } \\
\text { grego da Epístola de Tiago }\end{array}$ & $\begin{array}{l}\text { Retórica, } \\
\text { enunciação e } \\
\text { discurso }\end{array}$ \\
\hline \multirow{2}{*}{ 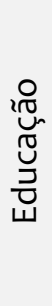 } & 2007 & $\begin{array}{l}\text { Márcia Regina Curado Pereira Mariano } \\
\text { As figuras de argumentação como estratégias discursivas. Um } \\
\text { estudo em avaliações no Ensino Superior }\end{array}$ & $\begin{array}{l}\text { Retórica, } \\
\text { argumentação } \\
\text { e semiótica }\end{array}$ \\
\hline & 2009 & $\begin{array}{l}\text { Isabel Cristina Michelan de Azevedo } \\
\text { A argumentação no Exame Nacional do Ensino Médio/2004: } \\
\text { percursos discursivos seguidos por jovens em processo de formação }\end{array}$ & $\begin{array}{l}\text { Retórica, } \\
\text { argumentação } \\
\text { e discurso }\end{array}$ \\
\hline 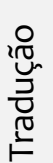 & 2004 & $\begin{array}{l}\text { Patrizia Collina Bastianetto } \\
\text { Legibilidade e Argumentação em textos traduzidos }\end{array}$ & $\begin{array}{l}\text { Argumentação, } \\
\text { semântica e } \\
\text { tradutologia }\end{array}$ \\
\hline
\end{tabular}

Fonte: Currículo Lattes de Lineide do Lago Salvador Mosca

Com base no Quadro 2, podemos notar que houve uma diminuição de pesquisas articuladas com a Literatura, os trabalhos que associaram a retórica e a argumentação ao discurso jornalístico se destacaram e que os campos do Direito, Religião e Educação mantiveram-se no horizonte de interesse do grupo de pesquisa. No entanto, esse perfil não foi mantido na década seguinte, uma vez que as investigações em maior número estarão centradas no campo da religião.

Outro destaque foi a abertura de Lineide Mosca para orientar trabalhos associados às Ciências da Educação - no mestrado (Quadro 1) e no doutorado (Quadro 2), o que foi particularmente importante para aqueles que pretendiam investigar as práticas de ensino de argumentação, os perfis dos exames de avaliação e os modos como os discursos pedagógicos circulam em sociedade. Como estava integrada, até 2013, à área de concentração Estudos do Discurso em Língua Portuguesa - Retórica e Argumentação, que integrava o Programa de Pós-Graduação de Filologia e Língua Portuguesa, ela acolheu entre seus orientandos de mestrado e doutorado pesquisadores com interesse em compor diferentes pesquisas ligadas à educação básica e ao ensino superior.

A receptividade a pesquisas dessa natureza se apoiava no fato de Mosca (1999) reconhecer a Retórica não como um mero exercício intelectual, mas como uma atividade humana, sustentada pelo estoque material cultural constituído pelas 
relações sociais, que integra o jogo interacional estabelecido sobretudo quando se quer persuadir o outro.

\section{Quadro 3 - Teses de Doutorado (segundo decênio dos anos 2000)}

\begin{tabular}{|c|c|c|c|}
\hline \multicolumn{3}{|r|}{ Dados da pesquisa } & \multirow{2}{*}{\begin{tabular}{l}
\multicolumn{1}{c}{ Interface } \\
Retórica e \\
argumentação
\end{tabular}} \\
\hline 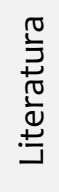 & 2011 & $\begin{array}{l}\text { Elizabete Enz Hubert } \\
\text { Relações discursivas nas sátiras a religiosos, atribuídas a Gregório } \\
\text { de Matos Guerra (1633-1696). Figuras e estratégias } \\
\text { argumentativas }\end{array}$ & \\
\hline \multirow{5}{*}{ 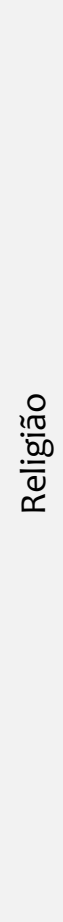 } & 2012 & $\begin{array}{l}\text { Moisés Olímpio Ferreira } \\
\text { A arte retórica nos discursos do apóstolo Paulo. As estratégias de } \\
\text { convencimento e persuasão frente à diversidade de auditórios }\end{array}$ & $\begin{array}{l}\text { Retórica, } \\
\text { argumentação } \\
\text { e semiótica }\end{array}$ \\
\hline & 2014 & $\begin{array}{l}\text { Márcia Selivon } \\
\text { Um estudo das representações, modelos e poder da palavra no } \\
\text { ritual neopentecostal }\end{array}$ & $\begin{array}{l}\text { Retórica, } \\
\text { argumentação } \\
\text { e discurso }\end{array}$ \\
\hline & 2018 & $\begin{array}{l}\text { Emilson José Bento } \\
\text { "Extra Ecclesian Nulla Salus": interação polêmica e suas } \\
\text { estratégias retórico-argumentativas na polêmica antidonatista } \\
\text { de Agostinho de Hipona }\end{array}$ & $\begin{array}{l}\text { Retórica, } \\
\text { argumentação } \\
\text { e discurso } \\
\text { religioso }\end{array}$ \\
\hline & 2019 & $\begin{array}{l}\text { João Claudemir Men } \\
\text { O discurso do corpo e a negociação da alma: o impacto das } \\
\text { emoções influenciando resultados. Argumentar, persuadir ou } \\
\text { negociar? }\end{array}$ & $\begin{array}{l}\text { Retórica, } \\
\text { argumentação } \\
\text { e análise do } \\
\text { discurso }\end{array}$ \\
\hline & 2019 & $\begin{array}{l}\text { Francisco Benedito Leite } \\
\text { "Ele está fora de si": Discurso Religioso e Linguagem Popular no } \\
\text { Evangelho conforme Marcos }\end{array}$ & $\begin{array}{l}\text { Argumentação } \\
\text { e discurso } \\
\text { religioso }\end{array}$ \\
\hline \multirow{3}{*}{ 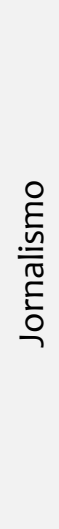 } & 2012 & $\begin{array}{l}\text { Cleonice Men da Silva Ramos } \\
\text { Revistas Impressas do mundo dos negócios: retórica e semiótica } \\
\text { em entrelaçamentos discursivos }\end{array}$ & $\begin{array}{l}\text { Retórica, } \\
\text { Argumentação } \\
\text { e semiótica }\end{array}$ \\
\hline & 2012 & $\begin{array}{l}\text { Eduardo Lopes Piris } \\
\text { O ethos e o pathos no hipergênero primeira página: análise } \\
\text { discursiva das edições de abril de } 1964 \text { dos diários Correio da } \\
\text { Manhã e O Globo }\end{array}$ & $\begin{array}{l}\text { Retórica, } \\
\text { argumentação } \\
\text { e análise do } \\
\text { discurso }\end{array}$ \\
\hline & 2014 & $\begin{array}{l}\text { Margibel Adriana de Oliveira } \\
\text { As notícias de crimes: uma análise retórico-argumentativa do } \\
\text { discurso jornalístico on-line por antecipação ao discurso jurídico }\end{array}$ & $\begin{array}{l}\text { Retórica e } \\
\text { argumentação }\end{array}$ \\
\hline
\end{tabular}




\begin{tabular}{|c|c|c|c|}
\hline : & 2013 & $\begin{array}{l}\text { Fabio Souza Trubilhano } \\
\text { Retórica Clássica e Nova Retórica nos recursos judiciais cíveis: a } \\
\text { construção do discurso persuasivo }\end{array}$ & $\begin{array}{l}\text { Retórica e } \\
\text { argumentação }\end{array}$ \\
\hline \multirow{2}{*}{ 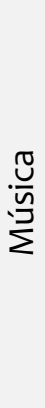 } & 2014 & $\begin{array}{l}\text { Adriano Dantas de Oliveira } \\
\text { A dimensão retórico-discursiva das canções buarqueanas: } \\
\text { mobilização de paixões na articulação tensiva opressão versus } \\
\text { liberdade e melos como prova de persuasão }\end{array}$ & $\begin{array}{l}\text { Retórica, } \\
\text { argumentação } \\
\text { e semiótica }\end{array}$ \\
\hline & 2014 & $\begin{array}{l}\text { Josely Teixeira Carlos } \\
\text { Fosse um Chico, um Gil, um Caetano...: uma análise retórica } \\
\text { discursiva das relações polêmicas na construção da identidade do } \\
\text { cancionista Belchior }\end{array}$ & $\begin{array}{l}\text { Retórica, } \\
\text { argumentação } \\
\text { e análise do } \\
\text { discurso }\end{array}$ \\
\hline 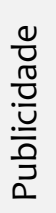 & 2015 & $\begin{array}{l}\text { Michel Marcelo de França } \\
\text { Discurso publicitário digital: semiose e retórica da trilogia Éthos, } \\
\text { Logos \& Páthos }\end{array}$ & $\begin{array}{l}\text { Retórica, } \\
\text { argumentação } \\
\text { e semiótica }\end{array}$ \\
\hline
\end{tabular}

Fonte: Currículo Lattes de Lineide do Lago Salvador Mosca

Como vemos no quadro 3, os cinco trabalhos realizados no campo religioso ocorreram do início ao final da década (de 2012 a 2019), estabeleceram interfaces entre diferentes teorias e recobriram fenômenos linguístico-discursivos bastante variados. Notamos também que o campo do jornalismo, associado ao da publicidade, continuaram sendo considerados pelos orientandos de Lineide Mosca, e que a área de Música surge como um campo com potencial significativo para a análise discursivoargumentativa, promovendo, inclusive, novas interfaces.

Observamos, enfim, que Lineide do Lago Salvador Mosca não apenas é uma das grandes referências brasileiras dos estudos da retórica e da argumentação; ela também foi uma dedicada professora que, continuamente, procurou colocar seus orientandos e estudantes em contato com as pesquisas mais avançadas realizadas no Brasil e no mundo. Aliás, essa preocupação com a formação de alunos começou muito cedo, ao cursar o Magistério, e manteve-se, mesmo depois de obter o título de livredocente, até sua partida. Seu legado continua forte e pode ser visto nas múltiplas dimensões do seu trabalho. Como expressou o Departamento de Letras Clássicas e Vernáculas, o seu departamento na USP, “Perdemos uma profissional exemplar e uma colega gentil e querida por todos". 


\section{Produção acadêmica}

Para quem deseja conhecer a produção acadêmica de Lineide Mosca, selecionamos neste artigo suas publicações mais relevantes sobre retórica e argumentação, as quais se distribuem entre organização de livros de coletânea, capítulos em livros, artigos em periódicos acadêmicos, traduções e, durante a pandemia de covid-19, uma conferência ministrada no modo remoto pelo YouTube.

Após o seu Retóricas de ontem e de hoje, em 1997, a Professora Lineide publicou em 2006, pela editora Humanitas, Discurso, argumentação e produção de sentido, reunindo artigos provenientes dos Seminários de Pesquisa do PPG em Filologia e Língua Portuguesa realizados em 2002 e 2003. Nessa obra, os trabalhos abordam "o papel que a argumentação desempenha em diferentes tipos de manifestações discursivas, com vistas à produção do sentido e aos efeitos dele decorrentes" (MOSCA, 2006, p. 7). Em 2016, com uma nova turma de orientandos e integrantes do GERAR, publica pela Grácio Editor, de Coimbra, o livro de coletânea Retórica e Argumentação em Práticas Sociais Discursivas. E, em 2019, publica, em coautoria com Adriano Dantas Oliveira, Retórica e canção, pela editora Espaço Acadêmico. No ano seguinte, publica, com Paulo Sérgio de Proença, a obra Revisitando Dom Casmurro - aspectos retóricos em conexão com a Bíblia, pela editora Appris.

Quanto aos capítulos publicados em livro, além do clássico "Velhas e novas retóricas: convergências e desdobramentos" (MOSCA, 1997b), destacamos "Subjetividade e formação de opinião na mídia impressa" (MOSCA, 2002), "A teoria perelmaniana e a questão da afetividade" (MOSCA, 2004a), "Entre certezas e incertezas: a racionalidade própria da retórica e da argumentação” (MOSCA, 2016b), "Paixões, emoções e afetividade na trilha do tempo: lugar no discurso" (MOSCA, 2017) e "Novos tempos, Novos paradigmas: os desafios dos estudos retóricos na modernidade" (MOSCA, 2019a).

Nesses capítulos, é possível notar duas preocupações que acompanharam as reflexões da pesquisadora: (1) a reinscrição da antiga retórica na contemporaneidade por meio da nova retórica perelmaniana em articulação com distintos quadros teóricos das ciências da linguagem, especialmente a semiótica, a enunciação e as teorias do discurso; (2) a questão da subjetividade na argumentação, sobretudo no que diz respeito ao pathos e à afetividade como recurso argumentativo.

Essa mesma vocação temática pode ser encontrada igualmente em seus inúmeros artigos, tais como "A vitalidade da retórica: atravessando os séculos" (MOSCA, 2003), "O discurso da imprensa na formação da identidade nacional 
portuguesa, reflexões a partir de A jangada de pedra, de José Saramago" (2004b), "A atualidade da Retórica e seus estudos: encontros e desencontros" (2006b), "O espaço tensivo da controvérsia: uma abordagem discursivo-argumentativa" (2007b), "Discurso e má fé: do elogio à perversidade - estratégias retóricas em campanhas políticas eleitorais" (2011) e "A importância da Nova Retórica para a compreensão de textos opinativos" (GRÁCIO; MOSCA, 2016), este em coautoria com Rui Alexandre Grácio. Nesses artigos, percebemos uma pesquisadora dedicada a consolidar uma abordagem de análise discursivo-argumentativa capaz de abranger objetos tão distintos como o são o discurso político-publicitário das campanhas eleitorais e o discurso literário relacionado a uma identidade nacional.

Lineide Mosca também foi uma pesquisadora dedicada à tradução, tendo, inclusive, presidido um centro de traduções e dirigido um respeitado periódico acadêmico especializado na área. Atuou como Presidente da Comissão de Publicações do Centro Interdepartamental de Tradução e Terminologia (CITRAT), centro formalmente constituído em dezembro de 1992 pelos Departamentos de Letras Clássicas e Vernáculas, Letras Modernas, Letras Orientais, Linguística e Teoria Literária e Literatura Comparada da FFLCH/USP. Além disso, por muitas décadas, foi editorachefe da revista TradTerm, publicação do mesmo Centro. Em sua atividade como tradutora e revisora técnica, é notória a sua tradução de Sistema da Moda, de Roland Barthes, publicada originalmente pela EDUSP, em 1979, bem como a revisão técnica, em parceria com a Profa. Dra. Irenilde Pereira dos Santos, de A sociedade refletida, de Eric Landowski, publicada pela Pontes, em 1992, e A Retórica, de Michel Meyer, publicada pela Editora Ática, em 2007.

Tais traduções refletiram-se em seus programas de disciplina, aulas, produção acadêmica e seminários de pesquisa do GERAR, contribuindo para a articulação de suas ideias em torno da retórica, argumentação e semiótica, uma de suas interfaces preferidas.

\section{Constituição e consolidação do Grupo de Estudos de Retórica e Argumentação (GERAR/USP/CNPq)}

Em seu próprio projeto de pesquisa, encontramos o interesse na difusão do conhecimento retórico e no congraçamento de diferentes pesquisadores em torno de um tema comum: 
Ao projeto, liga-se o GERAR (Grupo de Estudos de Retórica e Argumentação), coordenado pela líder do grupo e responsável pelo projeto em questão. Destaque é dado às Teorias da Argumentação, com suas diversas correntes e tendências, por constituir a argumentação o cerne da Retórica e ter um caráter universal, assim como considerar as diferenças culturais, inerentes às situações argumentativas. Estudam-se os mecanismos mobilizados para a consecução dos propósitos dos interlocutores nas mais diversas situações sociais, assim como os efeitos por eles produzidos 5 .

Sobre o GERAR - sua "menina dos olhos" - em recente entrevista concedida a um de seus orientados, Moisés Olímpio-Ferreira (2020), na revista Metalinguagens, a Professora Lineide conta como, em 1994, depois do curso de Retórica que coordenou na USP, tornou-se possível a criação do Grupo de Estudos de Retórica e Argumentação, pautado pela interdisciplinaridade e com foco na internacionalização. Esse grupo realmente foi um ponto alto na trajetória acadêmica de Lineide Mosca. E, se anteriormente tratamos do grupo como um espaço de "congraçamento" de pesquisadores e estudiosos da retórica, enfatizamos que a palavra é essa mesma - com o sentido de concórdia, harmonia, conciliação, mas a ela acrescentando o sentido de "convívio", "convivialidade".

Para Lineide, a busca de "formas de convívio humanizadoras, por meio da argumentação crítica e inteligente, que cultive o diálogo como forma de solução de problemas" (OLÍMPIO-FERREIRA, 2020, p. 12-28), ou as "normas negociadas de convivialidade" (MOSCA, 2006b, p. 3), necessárias para o gerenciamento e a superação de conflitos, seriam os pontos de encontro da retórica, "onde se cruzam, se separam e se confrontam diferentes pontos de vista, diversas visões de mundo, de tendências e de preferências" (2006b, p. 4). Ela nos transmitiu essa visão idealizada da retórica que teria, de fato, um papel único e imprescindível em nosso mundo conturbado. Assim, de modo muito prático, o congraçamento e o convívio eram as marcas registradas de todos os encontros e seminários do GERAR. Neles não podia faltar o intervalo (o coffeebreak!), para a interação entre todos os participantes ao redor de uma mesa farta de doces e salgados trazidos pelos organizadores do evento, seus orientandos. Essa mesa reuniu o grupo sempre renovado de orientandos, alunos, seguidores e admiradores, participantes de diferentes universidades e espaços do país ou do exterior.

No site do GERAR" ${ }^{6}$, o convite era aberto. Por exemplo: "Os Seminários de Pesquisa do GERAR são organizados, tendo em vista a interdisciplinaridade, tal como ocorreu com os três últimos, cujos enfoques foram relativos às contribuições dos

\footnotetext{
5 http://lattes.cnpq.br/9715573825703718
}

${ }^{6}$ Disponível em: http://gerar.fflch.usp.br/ 
Estudos do Discurso para as Ciências da Religião, as Ciências Jurídicas e as Ciências da Educação, respectivamente, com destaque para a Argumentação e a Retórica. Todos os interessados são muito bem-vindos aos Seminários e demais atividades do GERAR" (itálicos nossos).

Ao lado de sua capacidade de congregar, a capacidade de apoiar novos pesquisadores, pode ser constatada em recente homenagem de seus orientandos, que se concretizou no livro Retórica e discurso - Fronteiras e interfaces: das origens aos desdobramentos atuais, volumosa obra de 781 páginas organizada por Elizabete Enz Hubert e Emilson José Bento e publicada pela Editora Pontes em 2019, para a qual os leitores têm disponíveis duas resenhas (GRÁCIO, 2020; PISTORI, 2020).

Além dos seminários de pesquisa, dos encontros nos cafés e das confraternizações de final de ano, que favoreciam o estreitamento de laços afetivos entre os integrantes do grupo de pesquisa, Lineide Mosca vinha conduzindo os seminários de estudos do GERAR, reunindo nas manhãs de sábado não apenas seus orientandos, mas todos aqueles que desejassem debruçar-se sobre a leitura minuciosa de obras fundamentais do campo de investigação.

\section{Considerações finais: ou o legado de Lineide Mosca para os estudos de retórica e argumentação no Brasil}

A convivência com a Professora Lineide foi sempre agradável, enriquecedora e produtiva, poderiam atestar todos os seus orientandos e alunos. Em congressos e eventos em diferentes partes do Brasil e do mundo, ligados a retórica, argumentação e análise do discurso, ela sempre estava rodeada de alunos e admiradores de seu trabalho. E atenta a seus questionamentos! Com uma disposição ímpar, também era ótima companhia para passeios e descobertas culturais.

Outro aspecto admirável era sua constante atualização, especialmente no sentido da interdisciplinaridade. Observar as referências bibliográficas de seus cursos era ficar em contato com o que existia de mais recente na retórica e áreas correlatas. Estava antenada com o mundo e com o que nele acontecia. Ela nos fazia lembrar os dizeres de Cícero a respeito do que é a retórica: "todo conjunto de conhecimentos que possuem os homens mais instruídos" (Livro I, II, §5). A isso se acrescentam os textos sempre atuais com que ilustrava suas aulas e comunicações.

Queremos destacar, por isso, dois artigos recentes da Professora Lineide, publicados no Jornal da USP, que comprovam essa afirmativa. O primeiro é de 21 de 
outubro de 2019 e leva o título "O discurso presidencial”. Nele, Lineide critica com elegância e conhecimento retórico o pronunciamento:

Os sucessivos pronunciamentos do presidente denotam ausência de argumentação dialógica, que é um modo de gestão discursiva do desacordo e do conflito. Falta a ele o exercício do diálogo, em que várias vozes se cruzam e em que a voz única é expressão de autoritarismo. Os seus destinatários não são a gama variada da população do país, seu discurso destinando-se àqueles que o endossam e em que os demais figuram como adversários e até mesmo como inimigos. [...]

O que aflora é o domínio das paixões, como o repúdio, a raiva. A pergunta mais frequente que se ouve a respeito é: “o que vem por aí? qual a próxima?”. Tem-se um número enorme de distorções e falácias, advindas do mau manejo das frases, do léxico injurioso e das figuras retóricas de nível rude, que se afastam bastante daquilo que se consideravam na Antiguidade as qualidades do bom orador: clareza, concisão, propriedade e adequação, entre outras. Não basta dizer "sou flexível", "não sou autoritário" quando as atitudes não correspondem ao dizer e não produzem o efeito que se enuncia.

O segundo é de 4 de fevereiro de 2020 e denomina-se "“Coincidência retórica', não. Escolhas". Nesse artigo, Lineide responde a quem identificou como "coincidência" um discurso ("nazista") do secretário especial da Cultura em âmbito federal. Lineide rechaça essa afirmação de modo elegante, utilizando uma litotes ao final:

Tomando de perto os dois textos, o fundante, a matriz do texto de Goebbels, e o produzido para a situação descrita, do ex-secretário especial da Cultura, constata-se a "infelicidade" deste último, merecedor de todos os adjetivos de que foi alvo. $O$ texto pastiche nada mais é do que uma imitação grosseira de outras vozes, podendo soar como uma paródia ou imitação burlesca: apropriações léxicas e temáticas (heroica, nacional, imperativa) e decalques sintáticos ("ou então não será nada"), adaptações a equivalentes da outra cultura num exercício de paráfrase (ferreamente romântica por vinculadas às aspirações urgentes de nosso povo; com grande pathos por envolvimento emocional).

Por tudo que ficou aqui exposto, é bastante leviana a argumentação de que houve uma "coincidência retórica", sabendo-se que esta não é um fenômeno de superfície, mas que revela e desvela as intenções de seu produtor, por mais que tente disfarçá-las. O mostrarse já foi um grande mérito do vídeo, deixando menos obscuras as reais intenções. Prudência e virtude não são suas melhores qualificações.

Nesse excerto, observamos que Lineide Mosca, de modo perspicaz, observa como os recursos argumentativos foram mobilizados na composição de representações de mundo que "[...] estão estreitamente ligadas aos modos de sua 
expressão e são o resultado da criação de relações intersubjetivas no discurso [...]" (MOSCA, 1997b, p. 44), por isso as palavras do então secretário da Cultura são consideradas por ela escolhas que marcam uma posição discursiva produzida para um determinado tempo e lugar, segundo interesses claramente marcados e de acordo com a rede de vozes adotada como referência.

Ao longo deste breve artigo, procuramos, ao longo de seis seções, destacar que Lineide do Lago Salvador Mosca (1) colaborou com a inclusão dos estudos de retórica clássica e moderna no Departamento de Letras Clássicas e Vernáculas, no Programa de Filologia e Língua Portuguesa, nos primeiros anos de sua carreira acadêmica; (2) desenvolveu um percurso intelectual que foi marcado pela publicação da obra Retóricas de ontem e de hoje, embora estejam disponíveis ao público outras publicações que possam ser de interesse; (3) formou mestres e doutores que desenvolveram investigações que promoveram distintas interfaces em variados campos de conhecimentos e constituem um grupo de pesquisadores que colaboram com a produtividade do Grupo de Estudos de Retórica e Argumentação (GERAR/USP/CNPq).

Assim, esse nosso recorte da trajetória acadêmica da Professora Lineide Mosca é uma singela homenagem a uma mestra que inspirou uma geração de pesquisadores a consolidar o campo de investigação da argumentação no Brasil, que é constitutivamente interdisciplinar.

\section{REFERÊNCIAS}

BARTHES, Roland. Sistema da Moda. Tradução: Lineide Salvador Mosca. São Paulo: EDUSP, 1979; WMF Martins Fontes, 2009.

CICERON. De l'orateur. Tradução: Edmond Courbaud. 7. ed. Paris: Les Belles Lettres, 1985.

FIORIN, José Luiz. Argumentação. São Paulo: Contexto, 2015.

GRÁCIO, Rui Alexandre. Resenha do livro "Retórica e discurso - fronteiras e interfaces: das origens aos desdobramentos atuais. homenagem à Professora Lineide do Lago Salvador Mosca". TradTerm, São Paulo, v. 35, p. 188-191, 2020. DOI: http://doi.org/10.11606/issn.23179511.v35iop188-191

GRÁCIO, Rui Alexandre; MOSCA, Lineide Salvador. A importância da Nova Retórica para a compreensão de textos opinativos. ReVEL - Revista Virtual de Estudos Linguagem, v. 14, n. 12, 2016. Disponível em: http://www.revel.inf.br

HUBERT, Elizabete Enz; BENTO, Emilson José. Apresentação. In: (org.). Retórica e discurso. Fronteiras e interfaces: das origens aos desdobramentos atuais. Homenagem à professora Lineide do Lago Salvador Mosca. Campinas: Pontes, 2019. p. 9-29. 
LANDOWSKI, Eric. A sociedade refletida. Ensaios de sociossemiótica. Tradução: Eduardo Brandão. Revisão técnica da tradução: Lineide Salvador Mosca e Irenilde Pereira dos Santos. São Paulo; Campinas: EDUC; Pontes, 1992.

MEYER, Michel. A retórica. Tradução: Marly N. Neves. Revisão técnica: Lineide Salvador Mosca. São Paulo: Ática, 2007.

MOSCA, Lineide Salvador. Subjetividade no editorial: uma análise retórico-argumentativa da adjetivação. São Paulo, 1990. 406f. Tese (Doutorado em Filologia e Língua Portuguesa) Faculdade de Filosofia, Letras e Ciências Humanas, Universidade de São Paulo.

MOSCA, Lineide Salvador (org.). Retóricas de ontem e de hoje. São Paulo: Humanitas, 1997a.

MOSCA, Lineide Salvador. Velhas e novas retóricas: convergências e desdobramentos. In: (org.). Retóricas de ontem e de hoje. São Paulo: Humanitas, 1997b. p. 17-54.

MOSCA, Lineide Salvador. Subjetividade e formação de opinião na mídia impressa. In: GHILARDI, Maria Inês; BARZOTTO, Valdir Heitor (org.). Nas telas da mídia. Campinas: ALB \& Alínea, 2002. p. 9-22.

MOSCA, Lineide Salvador. A vitalidade da retórica: atravessando os séculos. Língua e Literatura, São Paulo, n. 27, p. 149-169, 2003. DOI: https://doi.org/10.11606/issn.25945963.lilit.2003.105444

MOSCA, Lineide Salvador. A teoria perelmaniana e a questão da afetividade. In: OLIVEIRA, Eduardo Chagas (org.). Chaïm Perelman: direito, retórica e teoria da argumentação. Feira de Santana: Universidade Estadual de Feira de Santana \& Núcleo Interdisciplinar de Estudos e Pesquisa em Filosofia, 2004a. p. 129-140.

MOSCA, Lineide Salvador. O discurso da imprensa na formação da identidade nacional portuguesa, reflexões a partir de A jangada de pedra, de José Saramago. Filologia e Linguística Portuguesa, São Paulo, n. 6, p. 255-266, 2004b. DOI: http://doi.org/10.11606/issn.2176-9419.voi6p255-266

MOSCA, Lineide Salvador (org.). Discurso, argumentação e produção de sentido. São Paulo: Humanitas, 2006a.

MOSCA, Lineide Salvador. A atualidade da Retórica e seus estudos: encontros e desencontros. Congreso Virtual del Departamento de Literaturas Románicas de la Universidad de Lisboa sobre 'Retórica', 1, 2005. Actas del [...]. Departamento de Literaturas Românicas, Universidade de Lisboa, Lisboa, 2006b. Disponível em: http://dlcv.fflch.usp.br/sites/dlcv.fflch.usp.br/files/lineioo2_o.pdf

MOSCA, Lineide Salvador. Discurso, argumentação e persuasão: uma revisão crítica. São Paulo, 2007a. 254f. Tese (Livre Docência em Filologia e Língua Portuguesa) - Faculdade de Filosofia, Letras e Ciências Humanas, Universidade de São Paulo.

MOSCA, Lineide Salvador. O espaço tensivo da controvérsia: uma abordagem discursivoargumentativa. Filologia e linguística portuguesa, São Paulo, n. 9, p. 293-310, 2007b. DOI: https://doi.org/10.11606/issn.2176-9419.voigp293-310

MOSCA, Lineide Salvador. Discurso e má fé: do elogio à perversidade. Estratégias retóricas em campanhas políticas eleitorais. EID\&A - Revista Eletrônica de Estudos Integrados em 
Discurso e Argumentação, llhéus, n. 1, p. 64-71, 2011. Disponível em: http://periodicos.uesc.br/index.php/eidea/article/view/369

MOSCA, Lineide Salvador (org.). Retórica e Argumentação em Práticas Sociais Discursivas. Coimbra: Grácio Editor, 2016a.

MOSCA, Lineide Salvador. Entre certezas e incertezas: a racionalidade própria da retórica e da argumentação. In: (org.). Retórica e Argumentação em Práticas Sociais Discursivas. Coimbra: Grácio Editor, 2016b. p. 11-16.

MOSCA, Lineide Salvador. Paixões, emoções e afetividade na trilha do tempo: lugar no discurso. In: FIGUEIREDO, Maria Flávia; RAMÍREZ VIDAL, Gerardo; FERREIRA, Luiz Antônio (orgs.). Paixões aristotélicas. Franca: UNIFRAN, 2017. v. 2. p. 15-29.

MOSCA, Lineide Salvador. Novos tempos, Novos paradigmas: os desafios dos estudos retóricos na modernidade. In: HUBERT, Elizabete Enz; BENTO, Emilson José (org.). Retórica e discurso. Fronteiras e interfaces: das origens aos desdobramentos atuais. Homenagem à professora Lineide do Lago Salvador Mosca. Campinas: Pontes, 2019a. p. 213-225.

MOSCA, Lineide Salvador. O discurso presidencial. Jornal da USP, São Paulo, 21.out. 2019b. Disponível em: https://jornal.usp.br/?p=280184

MOSCA, Lineide Salvador. "Coincidência retórica”, não. Escolhas. Jornal da USP, São Paulo, 04.fev. 2020a. Disponível em: https://jornal.usp.br/?p=299023

MOSCA, Lineide Salvador. 1 vídeo (2h25m46s). Retórica e Argumentação na trilha do tempo. Publicado pelo Canal Discursividade, 2020b. Disponível em: https://www.youtube.com/watch?v=zQt2B211xX4\&ab_channel=Discursividade

OLÍMPIO-FERREIRA, Moisés. Entrevista com Lineide do Lago Salvador Mosca. Entrevistada: Lineide Salvador Mosca. Revista Metalinguagens, São Paulo, v. 7, n. 1, p. 12-28, 2020. Disponível em: http://seer.spo.ifsp.edu.br/index.php/metalinguagens/article/view/742

OLIVEIRA, Adriano Dantas de; MOSCA, Lineide Salvador. Retórica e canção. São Paulo: Editora Espaço Acadêmico, 2019.

PIERRO, Bruno de. Galhos e raízes da árvore da ciência. In: PESQUISA FAPESP, n. 249, nov. 2016. Disponível em: https://revistapesquisa.fapesp.br/galhos-e-raizes-da-arvore-da-ciencia/.

PISTORI, Maria Helena Cruz. Resenha de "Retórica e discurso - fronteiras e interfaces: das origens aos desdobramentos atuais. homenagem à Professora Lineide do Lago Salvador Mosca". EID\&A - Revista Eletrônica de Estudos Integrados em Discurso e Argumentação, Ilhéus, v. 20, n. 1, p. 286-292, 2020. DOI: https://doi.org/10.17648/eidea-20-2652

PROENÇA, Paulo Sérgio de; MOSCA, Lineide Salvador. Revisitando Dom Casmurro: aspectos retóricos em conexão com a Bíblia. Curitiba: Appris Editora, 2020.

SOUZA, Roberto Acízelo. $O$ império da eloquência: retórica e poética no Brasil oitocentista. Rio de Janeiro: EdUERJ; EdUFF, 1999. 